TECHNICAL NOTES AND MANUALS

\title{
Tax Administration in Small Economies
}

Maureen Kidd

Fiscal Affairs Department 
INTERNATIONAL MONETARY FUND

Fiscal Affairs Department

Tax Administration in Small Economies

Prepared by Maureen Kidd

Authorized for distribution by Carlo Cottarelli

April 2010

DISCLAIMER: This Technical Guidance Note should not be reported as representing the views

of the IMF. The views expressed in this Note are those of the authors and do not necessarily

represent those of the IMF or IMF policy.

\begin{tabular}{|l|l|}
\hline JEL Classification Numbers: & $\mathrm{H} 20, \mathrm{H} 24, \mathrm{H} 25$ \\
\hline Keywords: & $\begin{array}{l}\text { tax administration, organization structure, small and micro economies, } \\
\text { organizational models }\end{array}$ \\
\hline Authors' E-Mail Addresses: & maureenkidd@hotmail.com \\
\hline
\end{tabular}




\title{
TECHNICAL NOTES AND MANUALS
}

\section{Tax Administration in Small Economies}

\author{
Maureen Kidd
}

Key questions to be answered:

- What is a small economy? What is a micro economy?

- What are the general principles of tax administration organization?

- What are the characteristics of a tax administration in small and micro economies?

- What makes the general principles difficult to apply?

- How can the general principles be adapted to better suit small and micro tax administrations?

- What are possible organizational models for small/micro tax administrations?

- How do the organizational solutions address the specific challenges of small/micro tax administrations e.g. integrity?

Choosing the right organization structure is a key component of any program of tax administration reform and modernization. It creates a solid platform from which all other enhancements can follow. Organizations and agencies involved in providing advice to governments on modern tax administration have developed principles that should drive decisions on organization structure. The question that this note will discuss is how these principles either address or can be adapted to the needs of small and micro economies.

\section{What is a small economy? What is a micro economy?}

There is a range of ways to define a small economy, including population, geography or gross domestic product (GDP) and these measures are often strongly related. Using population as the criterion, research on economic activity in small countries describes populations lower than 10 million as small ${ }^{1}$. This would mean that 134 countries are considered small by this standard today.

Note: Maureen Kidd is a former Director-General of the Canada Customs and Revenue Agency and member of the IMF's Fiscal Affairs Department roster of experts.

${ }^{1}$ World Bank: Defining a Small Economy. 2007. 
Conversely, the British Commonwealth has determined that populations of less than 1.5 million are considered small. By this measure, 45 developing countries are small-fully one-third of countries that the World Bank deems to have developing country status. These countries are found largely and almost evenly across the Caribbean, East Asia and the Pacific and Africa with a few countries found in South Asia, the Middle East and Europe. Amongst the group of 45 countries, per capita GDP ranges from $\$ 400$ to $\$ 9,000$ (with countries like the Bahamas or Cyprus at the higher end of the range). ${ }^{2}$

Population is likely the most useful criterion to use for the purposes of defining small and micro economies in order to review and develop advice on tax administration organization structure. It strikes to the number of taxpayers over which the tax administration needs to have oversight and the attendant compliance issues. For the purpose of this technical note, small and micro economies will be treated as one as there is little to no differentiation in the organizational advice offered.

\section{What are the general principles of tax administration organization?}

There are principles of tax administration organization design that are generally accepted as providing not only the best basis for reform and modernization but also the best conditions for the daily management and monitoring and operations of the business of tax administration itself. These principles include:

- an organization based on the key functions of tax administration, rather than separate business units to deal with each different tax for which the administration may be responsible. Current thinking in this regard is that a tax organization that structures its work in logical groupings of core functions that encompass all taxes is more efficient, has a better picture of overall taxpayer compliance and is able to better leverage a number of synergies from similar work being done in the same work unit

- an organization that is integrated i.e. that all national taxes are administered by one organization and that there are not different departments for income taxes, for sales taxes, and possibly also for property taxes and for any other taxes or licenses which the government may have decided to levy

- an organization that recognizes that both the needs and compliance challenges of large, medium and small taxpayers are quite different and tailors its programs accordingly. A segmented approach also reflects the organization's interest in identifying its areas of greatest risk and in focusing its efforts in this regard.

When determining organizational structure, tax administrations also consider two further dimensions: (1) the need for policy direction and monitoring that is separate and apart from operational delivery and (2) the requirement for specialization.

${ }^{2}$ Countries within this group with higher per capita GDP may need to consider specialized approaches to large and medium taxpayers and this will be discussed in another technical note. 
For large and medium administrations, with adequate resources and an appropriate number of staff, these principles translate to an organization structure where there is a strong headquarters, organized by key tax administration functions, and which develops policies and programs, allocates operational results, sets goals and targets, measures the results and adjusts approaches as a consequence of those results. A network of operational offices (depending on the number of offices, sometimes organized into larger regions) is established close to the concentration of the taxpayer base and to deliver the tax administration's programs and services.

In the larger government context, tax administrations can be a department within the Ministry of Finance, a separate department of government or in some countries, an autonomous agency. No matter where the administration sits or how it reports to government, the Minister of Finance usually has direction or oversight of the tax administration.

Figure 1 shows a classic organization chart of a tax administration in a large or medium economy and several features can be noted:

- a headquarters arm that includes separate divisions or units for: (1) taxpayer service and education, including registration; (2) returns processing and payment; (3) audit and investigations; (4) enforced collections; (5) tax operations policy; (6) objections and appeals; and (7) a range of classic corporate functions e.g. human resources

Figure 1. Typical tax administration organization structure- large and medium economies

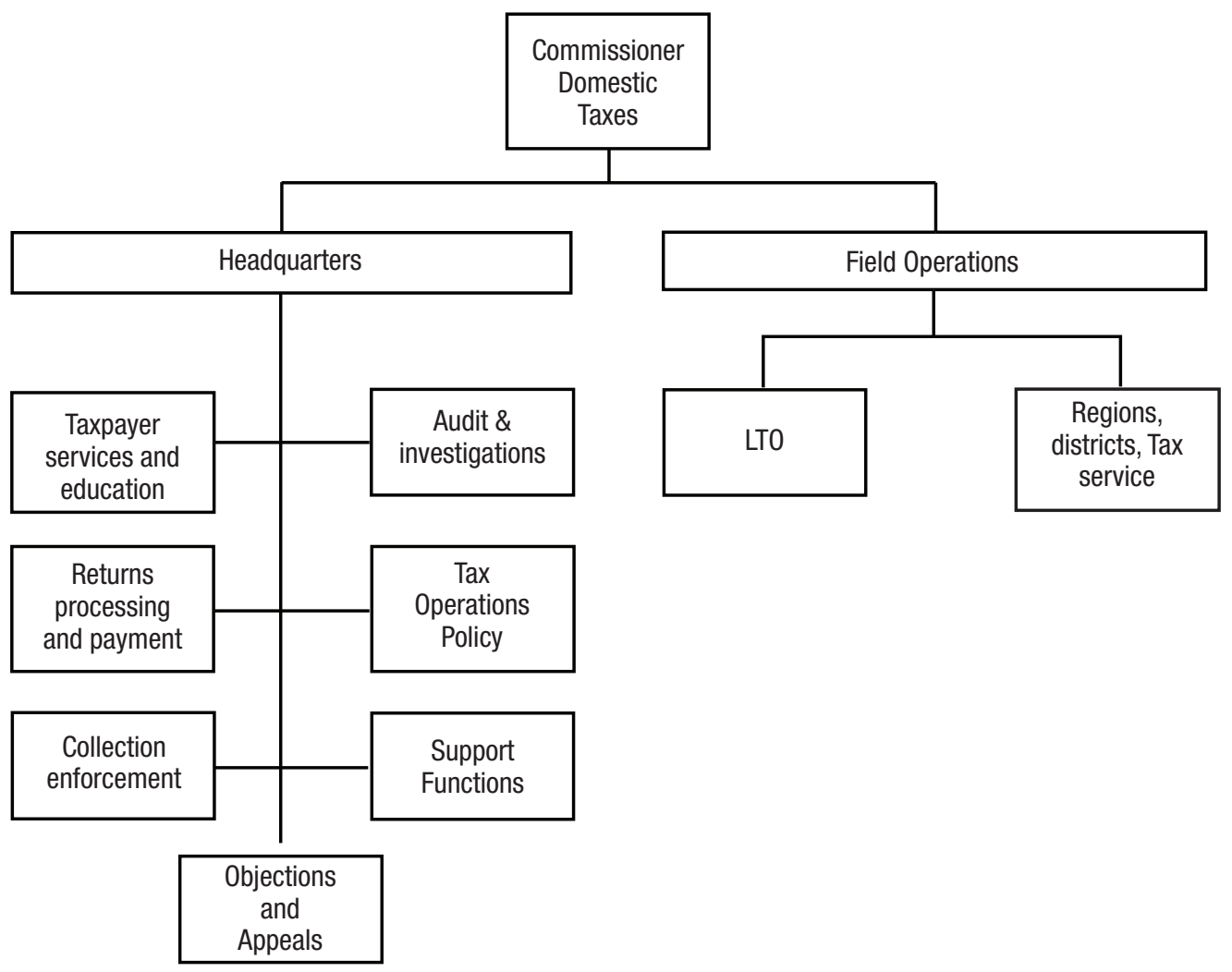


- an operational arm that can include a network of regional offices that would usually include offices that are segmented for large taxpayers (at a minimum) and for medium taxpayers.

\section{What are the characteristics of tax administration in small and micro economies?}

It is first important to consider the nature of small and micro economies and to identify

what in fact makes them different. Many of the following characteristics are structural in nature and beyond the policy capacity of any government to adequately influence or to address. They include but are not limited to:

-a low population base

- physical isolation

- geographic dispersal and isolation from markets

— small markets and relatively open economies

- a narrow base for revenue generation

—a propensity for disruption by natural disaster

This translates to a complicated operational reality for the tax administration:

The workforce is usually quite small and the domestic labor market often does not have an ample supply of the education and experience needed by tax administrations.

The overall budget that government can make available to the tax administration is small and there are many typical features of an organization structure that cannot be instituted for lack of financing e.g. separate offices for operations.

Overall technical capacity is low, as a reflection of the labor market from which staff has been recruited as well as limitations on the amount of training that can be offered on the job or provided elsewhere.

Given the small population base, civil society is quite small and many government officials and private sector business people are well known to each other. This can at times result in political direction to the tax administration on operational cases as a result of representations made by taxpayers to the political level.

Governments in small economies can have difficulty retaining adequate legal counsel and this has a direct impact on overall compliance - as the taxpaying population assumes that government has limited capacity to pursue non-compliance through legal means.

Against this operational reality, the tax administration is usually under almost daily pressure to report its revenue collection results and to meet or surpass targets. In some cases, revenue is the only measure of the administration's performance so it is not surprising that other key 
components of tax administration are given little attention. The tax administration usually sits under the direct supervision of a Financial Secretary and the level of delegation of authority for daily management can vary greatly.

\section{Many tax administrations in small and micro economies are also given responsibility} for the collection of a number of fees and charges (e.g. vehicle registration, driver licenses) as government chooses to not create separate structures for these purposes. Nevertheless, they can serve to detract from the tax administration's key role in the administration and enforcement of national revenue laws, although can provide synergies and opportunities for compliance enforcement if they are properly exploited.

All of these factors have some critical consequences for the overall shape and structure of the actual organization of the tax administration. A detailed function-based structure as might be found in large and medium economies is often not possible given their small size. Some administration by tax type is usually present and there is frequently limited attention to taxpayer education, enforced collection and audit. Use of basic risk management techniques is rare and the operational emphasis is on collections.

Box 1 describes the tax administration in two small economies—Fiji and the Seychelles.

\section{Box 1. Tax administration organization in Fiji and the Seychelles}

Fiji. The FIRCA (Fiji Islands Revenue and Customs Authority) Act 1998 was enacted to establish a revenue authority that combined the previous tax and customs departments under a single executive management structure with supervision by a board of directors. The tax administration organization is part of FIRCA.

FIRCA embarked on a major restructuring to integrate several core tax and customs activities on a functional basis. This attempt at a close to full integration of tax and customs resulted in a complex matrix structure with seven functional managers overseeing a mix of tax-type, functional and segmented organizational units. The operational reality was that this structure was too complex for the size of the organization and appeared to diminish the importance of customs. In 2008, FIRCA opted to reestablish core tax and customs competencies in two functional departments that remain part of FIRCA. A third department will continue to integrate management support services at the corporate headquarters.

The domestic taxes branch is now led by a general manager and supported by three subordinates for revenue collection, audit compliance and debt management. This organization has some aspects of integration and is partially function-based but also has limitations e.g. no focus on taxpayer service or assessment and collections and no distinction between headquarters and operations.

(continued on next page) 


\section{Box 1. (concluded)}

Seychelles. The Seychelles Revenue Commission (SRC) was created on 1 January 2008 with some of the features of a revenue authority but without a governing board. The SRC Act 2008 brought together the domestic tax and trade taxes divisions as well as the compliance division of the Social Security Fund. The organization is led by a Commissioner and the creation of a position of Deputy Commissioner is contemplated. The heads of the domestic taxes and trade taxes divisions are assistant commissioners within the new organization. Domestic tax division has close to 40 staff and this is planned to increase to 60 in 2010. The SRC has some autonomy from the public service, particularly in the area of human resources.

The proposed organization for the domestic taxes division foresees three units - one for taxpayer services, one for enforcement and one for audit. With the exception of a sub-unit that will focus on large taxpayers, there is a limited distinction between headquarters functions and operations.

\section{What makes the general principles difficult to apply?}

As described previously, large and medium tax administrations are usually designed around the principles of function, integration and segmentation, with attention to a desirable separation between policy direction and monitoring, and the need for specialization. The circumstances that face small and micro economies make full application of these principles difficult in a number of ways.

The small size of the tax administration may make a function-based structure and specialization impractical. Many tax administrations in small and micro economies have a workforce numbering 100 or less. The geography of the country often dictates that the entire workforce is housed in one location, usually in the center of the capital. These factors make the idea of a completely separate headquarters that directs separate tax operations located across the country a complicated proposition. More typically, one audit unit exists that will set audit programs, decide audit selection, carry out audits and monitor audit results all from one point within the organization. There are simply not enough people to merit the creation of a full function-based organization. The ability to establish specializations or centers of excellence is hampered by the very fact that too few staff members are available to fully develop in only one area. By default, staff are multi-disciplined but often spread thin.

Their historical mandate, when combined with questions of capacity, works against an integrated administration. Tax administrations in small and medium economies have the traditional responsibility for income tax as their core mandate. For various reasons, they have often done an inadequate job in this regard. As new taxes are instituted (e.g. a VAT), new departments or divisions are often created to respond to concerns that the existing department does not have the capacity to properly administer new taxes. Integration as a principle, therefore, is often set aside as a matter of expediency 
to ensure the success of the new tax. This however is not a unique problem for small economies, but potentially more problematic given the greater capacity constraints.

There is often a preponderance of fees and other service charges administered by the tax administration. Governments of small and micro economies often seek a multitude of ways to increase revenue collection and this can include a variety of fees and charges. In many cases, the responsibility for their collection is housed with the tax administration. These fees and charges can distract from the core business of tax administration but also need to be addressed in the organization structure. Administration of these taxes and fees takes up valuable management and staff time and thus contributes to the inability of a small or micro administration to develop a modern and effective tax administration.

There are often few large taxpayers and those that might be included in such a population are often foreign-owned and managed. As described earlier, small and micro economies generally have a narrow resource base and limited economies. There are few taxpayers that could be described as large, in the classic sense, and therefore most of these administrations do not segment their taxpayer base into small, medium and large taxpayer groups. They do not tailor their education and compliance programs according to taxpayer segment and tend to treat the taxpayer population with a one-size-fits-all approach.

The small population base can make full utilization of the tax administration's powers difficult for many tax officials. Small and micro economies have relatively small populations, often well under the 1.5 million used as a definition for the purposes of this note. The resulting effect is societies where the level of inter-connectedness is quite high and where people know a great deal about the businesses and professional dealings of others. This can create a challenging environment in which a tax administration must operate, as officials can at times feel constrained in exercising the full powers available to them under the law-given pressure from the community (or in some cases lack of cooperation from important sectors such as the banks). This underlines the need for a distinction between policy direction and operations so that a senior official in the tax administration is accountable for ensuring that the organization exercises its full mandate in any given area.

\section{How can the general principles be adapted to better suit small and micro tax administrations?}

The general principles i.e. function-based, integrated and segmented are in fact difficult for small and micro economies to implement in their entirety. There may however be approaches that are better suited to these economies while respecting the basic intent of the general principles. Organizations should be guided by the principles of efficiency and effectiveness and by a need for clear roles, mandates and accountabilities. The following general commentary serves to illustrate these points.

Function-based: The notion of the separation of headquarters from field operations (with the directive nature of that relationship) combined with a focus on tax administration specialties is a solution that 
works well in a large or medium economy. It is difficult if not impossible to strictly apply these principles in small administrations of less than 300 staff and micro administrations with less than 100.

But can the principles be acknowledged in some other way? For instance, even the smallest of organizations should be able to identify a small group (as small as one person) that focuses on program design and monitoring. Further, the senior official responsible for the small organization (with some support) can take on many of the roles usually attributed to headquarters e.g. directing work, allocating resources, reviewing results.

Specialization may be more difficult to achieve when there are simply not enough staff resources to develop specialties across the tax administration business. It may be possible though to create units that are expert in more than one subject e.g. taxpayer service and enforced collection and that are responsible for both program development and delivery. The result of their work would be overseen by the head of the tax administration, rather than the typical headquarters oversight present in a fully function-based organization.

Integrated: The argument that integration is not possible in a small or micro economy is more difficult to accept. Whether one or ten taxes are being administered, it makes sense for even the smallest workforce to be organized in such a way as to maximize efficiency and effectiveness. Separate units by tax type that offer the complete range of administrative functions do not make sense, no matter what the size of the organization. Small and micro administrations should be able to deliver integrated programs and services. It may be necessary to combine certain of these administrative functions in to the same organizational unit but nevertheless, the delivery model should be integrated.

Segmented: Small and micro economies will have some large taxpayers to deal with and they can represent a range of compliance risk. The large taxpayer population can often include foreignowned businesses that are equipped with the best advice on how to limit or minimize their tax burden. It is essential that the small and micro tax administrations have some means to respond to the challenges presented. But a full large taxpayer unit is often impossible to contemplate in an organization with fewer than 100 staff overall.

There are options that can be considered. An option available to small administrations would be to create a unit that focuses solely on large and medium taxpayers. This unit would handle all matters for these taxpayers, leaving the balance of the administration to deal with small taxpayers. For micro administrations where an organizational solution is not realistic, a large taxpayer program could be instituted, where officers from units across the department are designated as "large case" officers. The officers remain assigned to their current units (whether taxpayer service, audit or enforced collection, for instance) and a part of their daily work is to focus on the large taxpayer component. These are two scenarios where the objective of segmentation is achieved without an organizational unit being created.

Box 2 describes how Dominica, with fewer than 100 staff, is facing some of these challenges. 


\section{Box 2. Dominica. IRD organization and planned reforms}

Dominica is a small island economy with a population of less than 100,000 . The Inland Revenue Department (IRD) has less than 100 staff and is responsible for the administration of corporate and personal income tax, PAYE and VAT.

With the preparation for the introduction of the VAT in 2006, IRD opted to create a VAT project unit to manage the implementation process. This project unit evolved, on implementation, to a VAT unit within IRD. As result, IRD has managed tax administration by type of tax rather than in an integrated manner. Only taxpayer services and payment were centralized for all taxes while all other key functions were separately managed and administered e.g. audit, collections enforcement.

Over the past two years, the authorities have taken steps to: (1) fully integrate operations for all tax types; (2) create a unit to oversee large and medium taxpayers and another unit for small taxpayers; (3) establish common taxpayer service and processing; and (4) create a small subdivision to oversee operations and the future direction of the IRD.

\section{What are possible organizational models for small/micro tax Administrations?}

There are a number of options available to small and micro tax administrations that capitalize on organizational principles without burdening the organization with too much structure.

The principle of a function-based organization could be met in a few ways. Rather than a headquarters branch with specific units for all tax administration functions, a small programming and planning unit could be established, reporting directly to the senior official responsible for the tax administration. This unit would have responsibility for determining how tax administration functions would be delivered, of setting targets for the functional areas and monitoring their results. Resource allocation to the functional units would also be handled by the programming and planning unit. In this model, it is essential that roles and responsibilities are clearly articulated as it brings an element of matrix management to the organization, i.e. staff have a direct reporting relationship hierarchically but also have a reporting relationship vertically to the planning and programming unit.

Such an organization could also incorporate a large and medium taxpayer unit, bringing in to play the key principles of segmentation but set against the practical constraints of a small administration.

Figure 2 shows a tax administration organization that includes a program design and monitoring unit that has the key responsibilities of a typical headquarters function. This model creates a separate operational focus on large and medium taxpayers and on small taxpayers 
Figure 2. Suggested tax administration organization chart

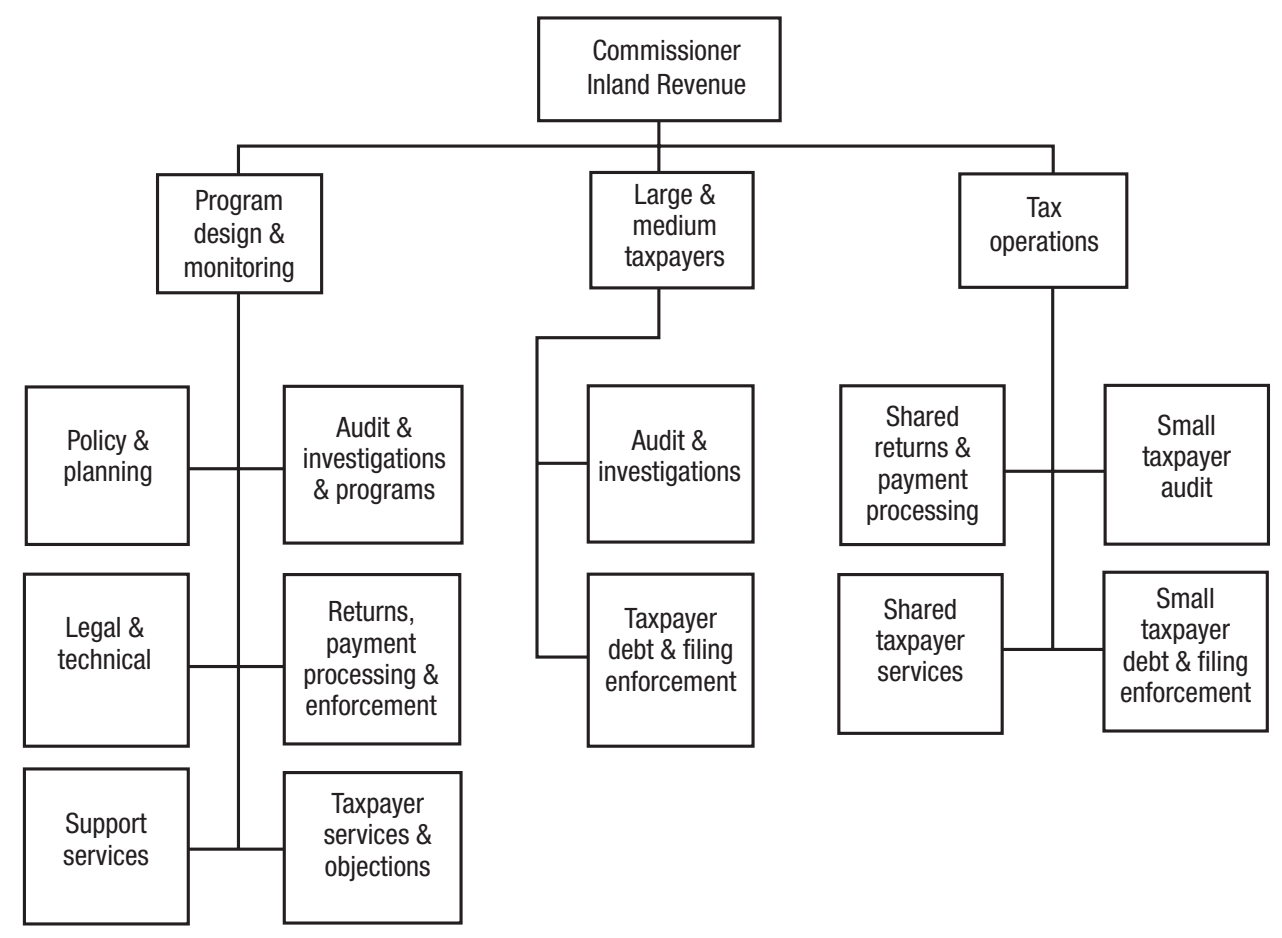

(through the tax operations unit—which also provides a single focus for returns and payment processing and for taxpayer services).

A micro organization may not have enough staff to consider the creation of a planning and programming unit. In this case, the head of the tax department could expect that the typical headquarters activity would occur in each of the functional units. For instance, the audit unit would not simply conduct audits but would undertake audit planning, determine targets and expected results, seek resources as needed. In essence, both headquarters and operational functions would be handled within each functional unit. In terms of segmentation, a full large and medium taxpayer office is impractical. What would make more sense would be to establish large taxpayer programs within each of the existing tax administration functions.

\section{How do the organizational solutions address the specific challenges of small/micro tax administrations e.g. integrity?}

This paper has reviewed a number of the challenges faced by small and micro tax administrations and most of these relate very directly to their size. The organizational solutions discussed all offer the possibility of more effective management and oversight and this will have direct effect on their ability to deal with the issue of integrity. An integrated organization eliminates silos and helps to ensure that appropriate checks and balances are in place. Equally, some form of functional oversight will ensure that no single individual or division within the organization has 
complete control over a process or over the affairs of a single taxpayer. Naturally, these operational enhancements should also be buttressed by an appropriate integrity strategy and plan.

\section{Key points for tax administration design}

- The key principles for tax administration organization are that the organization: (1) should be function-based, (2) should integrate delivery of all tax types and, (3) should address the specific needs of taxpayer groups by segmenting the taxpayer population in to large, medium and small taxpayers. All these principles can be adapted for small and micro economies.

- Integration of the administration of all taxes is possible no matter what the size of the tax administration. In fact, the challenges created by small size make integration even more important to ensure better efficiency.

- Function-based and segmentation remain solid principles to be followed and can be readily adapted to the specific needs of small and micro administrations. 